\section{Sechs Millionen Überstunden}

Nach Berechnungen der Bundeskurie der angestellten Ärzte der Österreichischen Ärztekammer (ÖÄK) müssten bundesweit rund sechs Millionen von Spitalärztinnen und Spitalärzten geleistete, jedoch bisher nicht entgoltene Überstunden nachgezahlt werden. Der Bundesobmann der angestellten Ärzte, Harald Mayer, in einer Aussendung: «Rund 12000 Ärztinnen und Ärzte sind nach unserer Hochrechnung davon betroffen.» Die geschätzte Nachzahlung betrage bundesweit rund 120 Millionen Euro, heisst es aus der ÖÄK. Nach aktuellen Umfragen halten 70 Prozent der österreichischen Spitäler die gesetzlichen Arbeitszeitregelungen für Ärzte nicht ein. «Die zuständigen Stellen, insbesondere das Arbeitsministerium, berühren die aufgezeigten Mängel bisher nicht. Alle Aufforderungen, diesen eklatanten Missstand durch die Einhaltung des Gesetzes respektive deutliche Strafen bei Verstössen zu beseitigen, sind bisher auf taube Ohren gestossen», kritisierte der Bundeschef der Spitalärzte. Überstunden seien zu bezahlen, auch die Spitalärztinnen und Spitalärzte hätten ein Recht darauf.

(Ö̈K)

\section{Deutschland: Auch alternative Medizin ist verordnungsfähig}

Die Kosten für Arzneimittel der alternativen Medizin müssen grundsätzlich von den Gesetzlichen Krankenkassen übernommen werden, wenn ein Arzt diese Präparate standardmässig einsetzt. Dieses Urteil fällte soeben das Sozialgericht Speyer.

Bei standardmässigem Einsatz von Arzneimitteln, die der alternativen Medizin zuzuordnen sind, muss demnach die GKV die Kosten übernehmen. Den Ausführungen der Richter zufolge sind hierbei das Arzneimittel und die vom Arzt gewählte Behandlungsmethode nicht an den Massstäben der Schulmedizin zu messen (Az.: S 7 KR 283/06), berichtet der Ärztenachrichtendienst änd.

Anlass für das Urteil war die Klage einer Patientin, die von ihrem Arzt zur Krebsbehandlung ein Mistelpräparat verschrieben bekommen hatte. Das verordnete Präparat wird regelmässig im Rahmen der anthroposophischen Therapie angewandt. Die Kasse verweigerte jedoch die Kostenübernahme mit der Begründung, das Präparat sei nicht verordnungsfähig.
Die Richter verwiesen darauf, dass das in diesem Fall verschriebene Präparat «Helixor» beispielsweise allein im Jahr 2003 insgesamt $125000 \mathrm{mal}$ verordnet worden sei - fast 65 Prozent aller Krebspatienten wurden damit behandelt.

Den Krankenkassen steht es nun offen, Berufung beim Landessozialgericht einzulegen.

(Der Kassenarzt)

\section{Krankenhausversorgung für Kinder in Gefahr}

Seit der Gesundheitsreform ist die Kinderversorgung in Krankenhäusern unterfinanziert, und darunter leidet die Qualität, hiess es auf der 39. Jahresversammlung des AKIK (Aktionskomitee Kind im Krankenhaus) in Frankfurt/ Main. Die vor kurzem veröffentlichten Ergebnisse der 4. Umfrage der BaKuK (Bundesarbeitsgemeinschaft Kind und Krankenhaus) sowie eine Resolution des 110. Deutschen Ärztetages 2007 in Münster wurden auf der Versammlung des AKIK vorgestellt. Demnach zeigt sich eine Tendenz, Kinder wieder vermehrt in Erwachsenenabteilungen, also nicht fachgerecht $\mathrm{zu}$ behandeln. Als Argument werde seit der Umstellung der Krankenhausfinanzierung auf die Fallpauschalenregelung immer wieder angeführt, dass sich Kindermedizin nicht rechne.

Deshalb hatte das AKIK im Oktober des letzten Jahres eine Onlinepetition beim Deutschen Bundestag eingereicht - bis heute ohne Reaktion. Auch eine gemeinsame Eingabe relevanter Fachverbände zur Qualitätssicherung in der stationären Kinderversorgung blieb bis heute ohne Antwort. «Die Politik dreht an den Stellschrauben bei der Versorgung kranker Kinder, ohne sich um die Folgewirkungen zu kümmern», kritisierte Julia von Seiche vom AKIK-Bundesverband.

(Der Kassenarzt)

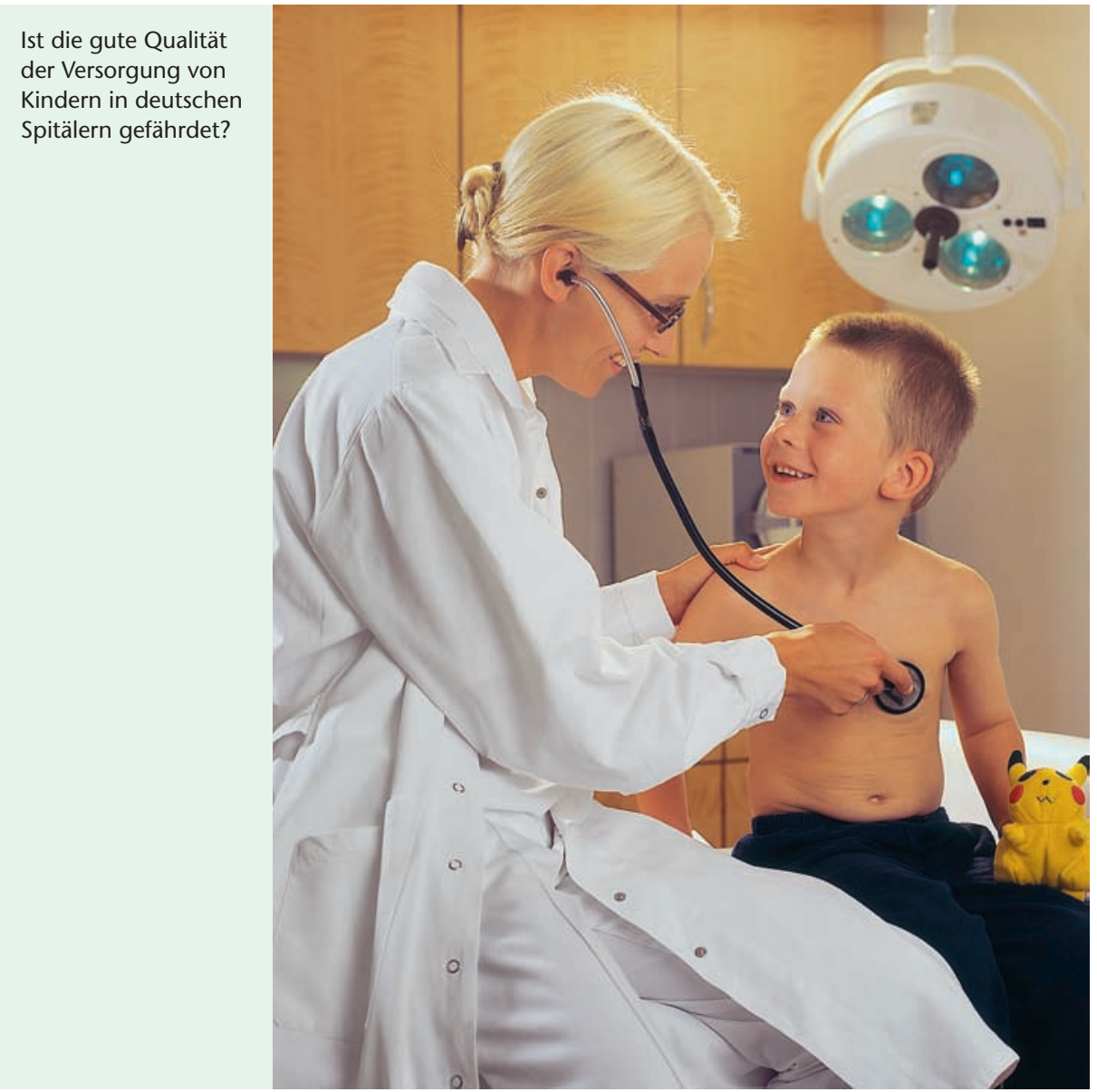

